\section{Unique technology for whole mouth protection}

Dental professionals were recently invited to an online educational webinar to hear about how Colgate Total delivers additional clinical benefits over using an ordinary fluoride toothpaste.

Presented by Dr Daniel

Bachteler (PhD), from

Colgate's Clinical Dental

Research team, the aim of the webinar was to demonstrate the important role triclosan/ copolymer technology plays in reducing plaque biofilm on oral hard and soft tissue, to help achieve whole-mouth protection.

Of the dental professionals who participated in the post webinar survey, $99 \%$ of them (out of 227) agreed that brushing with Colgate Total toothpaste delivers additional clinical benefits over using an ordinary fluoride toothpaste for both themselves and their patients.

Bacteria accumulate on soft tissues, which act as reservoirs, and recolonise tooth surfaces following mechanical plaque removal. Colgate Total works by reducing the bacteria load in the whole mouth, which in turn reduces the impact of bacterial recolonisation on tooth surfaces. Colgate Total also has unique sustained-release technology which delivers up to 12 hours of antibacterial protection even after eating and drinking. ${ }^{1-3}$

Colgate Total leaves less bacteria to repopulate and form dental plaque on tooth surfaces; this means toothbrushing with Colgate Total results in less dental plaque being formed before your next brush, leading to better oral health outcomes.

Take the opportunity to view this webinar for yourself and receive one hour of verifiable CPD (available until 31 December 2016) by visiting http://stage.colgateprofessional. co.uk/professional-education. For further information on the Colgate range visit www. colgateprofessional.co.uk.

1. Xu T, Deshmukh M, Barnes V M et al. Compend Contin Educ Dent 2004; 25(Suppl 1): 46-53.

2. Fine D H, Sreenivasan P K, McKiernan M et al. J Clin Periodontal 2012; 39: 1056-1064.

3. Kraivaphan P, Armonchat C, Triratana T. J Clin Dent 2013; 24: 20-24.

\title{
For advice on all aspects of legal services
}

Health and social care lawyers Hempsons advise dentists on all aspects of legal services relevant to dental practitioners. With a unique team that includes dual-qualified dentists and lawyers, Hempsons' people work with individual dental practitioners, professional associates and defence organisations.

Among its free services to clients, Hempsons offers a dental helpline providing up to ten minutes' free legal advice to dentists and members of their teams, and has recently published a revised version of its guidance on the GDC's fitness to practise procedures, which can be downloaded from the Hempsons website.
Hempsons also publishes regular newsletters, and has just launched its Dental Newsbrief, a round-up of some of the hot legal topics in the dental sector. Included in the first issue is a look at the advance preparations needed when selling your dental practice - and managing the CQC registration process, key points to agree with a landlord at Heads of Terms stage when entering into a lease of premises, and how to ensure you purchase your IT systems on the right terms. Download the Dental Newsbrief at www.hempsons.co.uk, where you can also register for future issues.

Need help? Call the helpline on 0207839 0278 or email c.morris@hempsons.co.uk.

\section{Make a point of contact}

Patient Connections from innovative dental software developers, Welltime, gives you the opportunity to communicate with your patients like never before.

An easy-to-use system that integrates seamlessly with your current digital facilities, Patient Connections allows you to send your patients comment forms and questionnaires after each appointment. The information you receive from these provides essential feedback with which you can improve your service.

Patient Connections also enables you to review and monitor this feedback in a simple manner - and then make use of it on your website. You will also be able to send patients pertinent articles and oral health tips through the programme, to offer them an even better service.

What's more, this eclectic programme allows you to send patients bespoke clinical advice and education, to support the advice you have given them in the surgery. This promotes better patient understanding and gives your patients the knowledge they need to take their own dental care into their hands.

To find out more about what Patient Connections could do for your practice and your patients, contact the expert team at Welltime today on 07999991337 , email sales@welltime.co.uk or visit www.welltime. co.uk.

\section{Will you learn lingual in 2017?}

After a successful debut year running his in-house course, Learning Lingual, Asif Chatoo is repeating the four-day course in 2017. The appeal for delegates who are committed to learning lingual is that tutoring isn't limited to any particular system but empowers them to feel at home with all aspects of the technique.

In its first year, the lingual course received highly positive feedback with delegates rating a total of 120 points out of 125 on five topics including content and the balance of theoretical and hands-on learning. Feedback also showed delegates valued the session where they could discuss cases both ongoing and planned.

Learning Lingual in 2017 will be hosted in Dr Chatoo's state of the art clinic on Wimpole Street, London and run over two modules: the introductory module on January 27 and 28 and the advanced on May 12 and 13.

Delegates can attend just one module or both and booking is open now. For more information see: www.londonlingualbraces.com/learning-lingual.php. 